\title{
A PARCERIA SINO-RUSSA E A DISPUTA PELA EURÁSIA: IMPERATIVOS GEOPOLÍTICOS E ALIANÇAS CONJUNTURAIS PELO CONTROLE DO CONTINENTE BASILAR
}

Ticiana de Oliveira Alvares ${ }^{1}$ Raphael Padula ${ }^{2}$

Resumo: O objetivo do artigo é analisar a parceria sino-russa atual, a partir das teorias geopolítica e de balança de poder. Argumenta-se que a força motriz desta aproximação na segunda década do século XXI se dá no sentido de diminuir a influência de potências extrarregionais sobre a Eurásia - sobretudo dos EUA, devido ao seu poder e presença oriundos do final da Guerra Fria - que representam uma ameaça estratégica comum aos interesses russo e chinês. Esse aspecto pode ser identificado nas diferentes frentes de cooperação sino-russa que possuem um caráter estratégico. Na impossibilidade de detalhar cada aspecto da parceria em um só artigo, esse trabalho dará luz à cooperação energética, à cooperação na Ásia Central e à integração eurasiática com liderança sino-russa.

Palavras-chave: China. Rússia. Eurásia. Geopolítica. Balança de Poder.

\section{THE SINO-RUSSIAN PARTNERSHIP AND THE DISPUTE FOR EURASIA: GEOPOLITICAL IMPERATIVES AND CONJUNCTURAL ALLIANCES FOR THE CONTROL OF THE BASILAR CONTINENT}

Abstract: The objective of this article is to analyze the current Sino-Russian partnership, focused on geopolitical and balance of power theories. The main argument is that the driving force of the reapproachment in the second decade of the 21st Century is to reduce the influence of extra-regional powers over Eurasia especially the United States, due to its condition of power and presence inherited from the end of the Cold War, representing a strategic common threat to Russian and Chinese interests. This aspect can be identified in the different fronts of the SinoRussian cooperation and carries a strategic character. Due to the impossibility to detail each aspect of the partnership in an article, this work will highlight energy cooperation, cooperation in Central Asia and the Eurasian integration process lead by China and Russia.

Keywords: China. Russia. Eurasia. Geopolitics. Balance of Power.

\section{LA PARCERIA CHINO-RUSA Y LA DISPUTA POR EURASIA: IMPERATIVOS GEOPOLÍTICOS Y ALIANZAS PARA EL CONTROL DEL CONTINENTE BASILAR}

Resumen: El objetivo del artículo es evaluar la actual parceria chino-rusa, basada en las teorias geopolíticas y de equilíbrio de poder. Se argumenta que la fuerza impulsora detrás de este acercamiento en la segunda década del siglo XXI es reducir la influencia de potencias extrarregionales em Eurasia, especialmente de los

\footnotetext{
1 Universidade Federal do Rio de Janeiro, Programa de Pós-Graduação em Economia Política Internacional, Rio de Janeiro, Brasil, ticiana.alvares@pepi.ie.ufrj.br, https://orcid.org/0000-0001-61104709

2 Universidade Federal do Rio de Janeiro, Instituto de Economia, Rio de Janeiro, Brasil, padula.raphael@gmail.com, https://orcid.org/0000-0002-8703-5171
} 
Estados Unidos, debido a su poder y presencia desde el final de la Guerra Fría, lo que representa um amenaza estratégica común a Russia y China. Este aspecto se puede identificar em los diferentes frentes de la cooperación chino-rusa que tienen um carácter estratégico. Como es imposible detallar cada aspecto de la parceria en un solo articulo, este trabajo destacará la cooperacioón energética, la cooperación en Asia Central y la integración euroasiática com el liderazgo chino-ruso.

Palabras clave: China. Rusia. Eurasia. Geopolítica. Equilibrio de Poder.

\section{Introdução}

A aproximação sino-russa ganha cada vez mais relevância no debate geopolítico e de relações internacionais em geral. Tal parceria vem gerando a percepção de ameaça por parte dos Estados Unidos, em relação à sua supremacia global, e é um elemento importante das transformações que vêm ocorrendo no mundo neste início de século XXI. Tal reaproximação, que se iniciou timidamente ainda na década de 1990, avançou a partir do primeiro mandato do Presidente Vladimir Putin, através do Tratado de Boa Vizinhança, Amizade e Cooperação (2001). Depois, ao longo da primeira década do século XXI, liderou importantes iniciativas como a Organização para Cooperação de Xangai (OCX) e a formação do grupo BRICS.

Entretanto, foi a partir do segundo decênio que a parceria alcançou outro patamar, resultante de sucessivos acontecimentos que aumentaram a percepção de ameaça vinda do ocidente. Para a China, o novo pivô asiático anunciado pelo então presidente estadunidense Barack Obama representava uma clara tentativa de contenção ao seu crescimento e influência na Eurásia. Do lado russo, a crise com a Ucrânia e as sanções econômicas e pressões estadunidenses e europeias dela decorrentes, reascenderam o sinal amarelo com relação à confiabilidade das relações com o ocidente e às vulnerabilidades econômicas e monetárias ${ }^{3}$. Assim, as hostilidades estadunidenses em relação à China e à Rússia contribuíram para uma reação, que impulsiona a atuação cada vez mais coordenada entre as duas potências, nos âmbitos bilateral, regional e global. No palco principal dessa disputa está a influência sobre a Eurásia.

$\mathrm{Na}$ literatura, apresentam-se diferentes avaliações sobre tal aproximação. $\mathrm{O}$ mais comum é colocar a parceria como uma aliança de conveniência e assimétrica

\footnotetext{
${ }^{3}$ A crise com a Ucrânia e suas consequências representou um ponto de virada na chamada "virada a leste" russa. Entretanto, uma sucessão de acontecimentos anteriores alertava os russos para a ameaça ocidental, dentre as quais se destacam: a expansão da OTAN para o leste, as revoluções coloridas e a Guerra da Geórgia, e a instalação de escudos antimísseis no leste europeu.
} 
em favor da China (GELBRAS, 2004, apud LUKIN, 2018; GAROUSOVA, 2014). Em especial, os autores ocidentais tentam criar cismas ou desacreditá-la, com argumentos economicistas, como se o pano de fundo da aliança fosse apenas os interesses econômicos visando a expansão chinesa e colocando a Rússia como uma parceira menor (The Economist, 2019) ${ }^{4}$. Outro argumento bastante comum é a impossibilidade de relações duradouras devido à vasta fronteira compartilhada entre os países, gerando contenciosos e alimentando rivalidades históricas (KAPLAN, 2017; LO, 2014).

Entretanto, esse artigo tem por objetivo analisar a atual parceria sino-russa por outro ângulo: da combinação entre uma explicação geográfica, a partir dos imperativos geoestratégicos, e as teorias da balança de poder. Ou seja, dos seus imperativos geopolíticos - enquanto desafios permanentes, associado às teorias da balança de poder - incorporando elementos da conjuntura. Argumenta-se que a força motriz desta aproximação na segunda década do século XXI se dá no sentido de diminuir a influência de potências extrarregionais sobre a Eurásia - sobretudo dos EUA, devido ao seu poder e presença oriundos do final da Guerra Fria - que representam uma ameaça estratégica comum aos interesses russo e chinês. Esse aspecto pode ser identificado nas diferentes frentes de cooperação sino-russa que possuem um caráter estratégico. $\mathrm{Na}$ impossibilidade de detalhar cada aspecto da parceria, esse artigo dará luz à cooperação energética, à cooperação na Ásia Central e à integração eurasiática, por considerá-las abrangentes e relevantes para o argumento $^{5}$. Ainda, a argumentação central se apoia na visão geopolítica clássica e na visão realista sobre disputa e balança de poder.

Para isso, o trabalho está dividido em cinco seções, além dessa introdução e das considerações finais. Na primeira, partindo-se do resgate das teorias geopolíticas clássicas (sobretudo de Halford Mackinder e Nicholas Spykman), apresentaremos a centralidade da Eurásia para a estratégia dos EUA no pós Guerra Fria, frente aos imperativos geopolíticos e geoestratégicos de China e Rússia em relação à potência dominante, amparados na visão estratégica de Zibigniew Brzezinski. Na segunda, traremos as teorias da balança de poder e da formação de alianças, apoiando-se sobretudo em Raymond Aron e Keneth Waltz. Na terceira,

\footnotetext{
${ }^{4}$ A edição de 27 de julho a 2 de agosto de 2019 trouxe como título "Brothers in Arms: the New Russia-China Partnership" alimentando a ideia de assimetria e da Rússia como parceira menor.

${ }^{5}$ Embora todas as formas de cooperação entre as duas nações pudessem ilustrar o argumento, em especial a cooperação financeira ou a militar, avaliamos a necessidade de focar nas apresentadas. Para uma visão mais detalhada da cooperação ver (ALVARES, 2020; LUKIN, 2018)
} 
apresentaremos a cooperação bilateral energética, e na quarta na Ásia Central, respectivamente como laboratórios de cooperação estratégica e de divisão de funções entre Rússia e China, além de suas complementaridades estratégicas. Na quinta, abordaremos a integração eurasiática como questão central da parceria sinorussa, ambas atendendo a um só tempo à geopolítica e à balança de poder. $\mathrm{O}$ trabalho se apoia em ampla literatura de especialistas sobre os temas abordados, em documentos e discursos oficiais de governos e instituições regionais e/ou multilaterais, e em dados da British Petroleum (BP) sobre energia.

\section{O lugar da Eurásia na geopolítica clássica e a estratégia dos EUA}

O geógrafo britânico Halford Mackinder (1904, 1919), ao formular sua teoria da supremacia do poder terrestre, apontou a Eurásia como o continente basilar para o equilíbrio ou disputa de poder global, por razões geográficas e materiais: massa territorial, população, recursos econômicos e industriais, e poder militar. Na sua visão, o Estado (ou aliança) que dominasse a Eurásia controlaria os rumos da política mundial.

$\mathrm{Na}$ verdade, Mackinder olhava para um autêntico domínio terrestre exercido pela Rússia na área central da Eurásia, a qual chamou de "área pivô" (1904) ou "heartland" (1919). Ainda, Mackinder se preocupava com a possibilidade de aliança ou domínio russo sobre o poder terrestre imperial alemão na área central da Europa. Na sua visão, o heartland possui um caráter estratégico na disputa pela Eurásia, e portanto pelo poder global, por ser uma fortaleza natural (cercada por mares gelados, estreitos, montanhas, vales e desertos), ter recursos potenciais, e sobretudo uma posição geográfica central que aufere ao Estado que a domina a capacidade de se expandir para todas as direções das bordas da Eurásia. A área circundante à pivô é denominada por ele como "crescente interno" ou "crescente marginal", que teria uma posição estratégica por ser o elo entre a região pivô e os oceanos. Mackinder aponta o conflito permanente entre os poderes terrestre e marítimo: a Rússia, situada no coração da Eurásia, que buscava se apropriar das regiões periféricas da Eurásia para alcançar os mares quentes, fazendo oposição ao poder marítimo da Inglaterra, que viria dos mares, das bordas da Eurásia em direção continental, pressionando e contendo o poder terrestre para dentro da Eurásia.

A partir disso, colocou em evidência o imperativo estratégico russo, revelado historicamente, e um dos pilares da política externa britânica, praticados desde a 
expansão do Império Habsburgo nos séculos XV-XVI. Para a Rússia, e qualquer poder continental, o objetivo permanente de se expandir de dentro para fora, para as bordas marítimas, buscando alcançar acesso ao mar e se tornar um poder anfíbio, numa força centrífuga. Para a Inglaterra, estabelecer um poder dividido e equilibrado na Eurásia, sem deixar que nenhuma potência ou aliança alcançasse a supremacia no continente, pois daria a esta uma vantagem relativa de poder, que ameaçaria a segurança e soberania da ilha britânica (PADULA, 2018a). Ou ainda, o princípio da política de contenção nas bordas da Eurásia, para evitar que o poder terrestre se tornasse anfíbio. Portanto, é no crescente marginal que se dá o grande embate entre o poder terrestre e o poder marítimo, pela supremacia da Eurásia.

A partir de um raciocínio lógico, é importante notar que uma aliança entre o poder terrestre russo do heartland e uma potência fronteiriça anfíbia como a China poderia formar um poder anfíbio capaz de ameaçar o equilíbrio de poder eurasiático. Vale lembrar que em artigo de 1942, "The Round World and the Winning of The Peace", Mackinder vislumbrou que no pós Guerra surgiria um polo de poder no Atlântico Norte, contraposto ao poder do Heartland da Eurásia, e que no futuro ascenderiam as chamadas "antigas civilizações orientais" da China e da Índia, com enorme potencial demográfico e geográfico que tenderiam a ser transformados em poder, formando novos polos de poder.

A partir dos conceitos geopolíticos mackinderianos, Nicholas Spykman, holandês radicado nos EUA, escreve a "America's Strategy in World Politics" em 1942, e "A Geografia da Paz", publicado em 1944, no ano seguinte à sua morte. Spykman (1942), preocupado em formular uma estratégia de Grande Potência para atuação dos EUA no pós-Segunda Guerra Mundial, sintetizou a sua geoestratégia como uma geopolítica de segurança, partindo de sua posição geográfica singular e do princípio da balança de poder.

O autor justifica a um só tempo o intervencionismo dos EUA no hemisfério ocidental e na Eurásia, aceitando a ideia de Mackinder de que este seria o continente basilar para o equilíbrio de poder global. Ele observa que há um paralelismo geográfico entre a América do Norte e a Eurásia, apresentando a mesma vizinhança (Atlântico Norte, Pacífico Norte e Mar Ártico). Portanto, cercamse mutuamente, estando próximas e interligadas por ilhas transoceânicas no Atlântico e no Pacífico - ainda mais com o avanço do poder aéreo e das tecnologias que proporcionam maior raio de alcance para a agressão militar. Assim, os EUA 
seriam uma ilha transoceânica cercada pelas extremidades da Eurásia, tendo como imperativo geoestratégico atuar permanentemente para promover o equilíbrio de poder no continente, e dominar e instalar bases avançadas nas ilhas transoceânicas. $\mathrm{Na}$ América (o hemisfério ocidental), por haver um desequilíbrio de poder tão assimétrico e revelado, e também pela proximidade e continuidade geográfica, a política estadunidense deveria ser de hegemonia promovendo a permanente dependência política de seus Estados, e afastando a projeção e alianças de potências externas. De acordo com o autor, caso uma potência (ou aliança) viesse a dominar a Eurásia, os EUA deveriam formar um sistema autárquico integrado sob sua hegemonia na América, colocando todos os seus recursos à sua disposição, para compensar o poder dominante da Eurásia e se proteger.

Na obra de 1944, Spykman apresenta o conceito estratégico de Rimland, oriundo da noção de Crescente Interno, destacando a geografia híbrida da região, com uma frente continental e outra oceânica, que lhe aufere um duplo problema de segurança, mas também uma dupla frente de expansão. O Rimland passa a ser a ideia central em torno da qual se desenvolve a estratégia para Spykman. Olhando para a história, afirma que as ameaças de unificação da Eurásia sempre vieram de potências do Rimland (França, Alemanha), e foram contidas por alianças entre o poder marítimo britânico com o poder terrestre russo ou outras potências da Eurásia. Portanto, os EUA deveriam atuar nas bordas da Eurásia, promovendo seu equilíbrio de poder. Com o objetivo de promover o equilíbrio de poder na Eurásia, o autor era contra a formação de uma federação de países na Europa e alertava para os destinos da Alemanha e do Japão, que não deveriam sair arrasados da Guerra (à exemplo do que acontecera com Alemanha em Versailles), por serem potências importantes para garantir o equilíbrio nas bordas ocidental e oriental da Eurásia, respectivamente.

Em suma, Mackinder decifrou os imperativos geoestratégicos russos, colocando-a como grande ameaça na Eurásia, para revelar uma estratégia aplicada historicamente pela Inglaterra. Spykman coloca para os EUA o mesmo imperativo geoestratégico presente na política externa britânica na visão de Mackinder: trabalhar permanentemente pela promoção do equilíbrio de poder na Eurásia, atuando nas bordas (onde se localiza a China) e contendo o avanço de potências com posição geográfica central (como a Rússia), e ainda evitando alianças entre elas. A geopolítica de contenção praticada pelos EUA na Guerra Fria frente à URSS 
foi inspirada na visão de Spykman, que também influenciou o pensamento estratégico estadunidense desde então.

Influenciado por Mackinder e Spykman, Zbigniew Brzezinski, cientista político polonês radicado nos Estados Unidos, nas suas obras, coloca a Eurásia como continente basilar para a geopolítica americana (BRZEZINSKI; 1986, 1997, 2012), tanto por razões materiais quanto geográficas e de balança de poder (PADULA, 2018a). Em Game Plan (1986), Brzezinski explica a Guerra Fria a partir do confronto histórico entre uma potência terrestre transcontinental, em busca de saída para os mares quentes, e a potência marítima transoceânica, que passou a incluir as bordas da Eurásia em seu perímetro de segurança. Ou seja, para o autor, são as razões geográficas que explicariam o confronto bipolar e seus possíveis desdobramentos - e não as razões ditas ideológicas, que seriam apenas um fator adicional. É no momento que as duas potências identificam simultaneamente a atuação nas bordas da Eurásia como um imperativo estratégico que ocorre a colisão entre elas e se revela o embate geopolítico.

Já em Strategic Vision (2012), último livro do autor, a preocupação em como os EUA devem lidar estrategicamente com uma China ascendente e com a transição econômica e de poder do Ocidente para o Oriente é o tema central. O autor coloca que a Eurásia é o centro da geopolítica global, sendo a ascensão da China o principal desafio de longo prazo. Nesta obra, os elementos geográficos e de balança de poder aparecem bem conjugados na formulação da estratégia americana. Para enfrentar o crescimento chinês, os EUA deveriam atuar para fortalecer a Europa e agir para enquadrar a Rússia e a Turquia dentro do projeto de "ocidente expandido" ou "alargado", aceitando a política e os valores do "ocidente". A promoção deste "ocidente expandido", alcançando o Japão, Coreia do Sul e demais aliados do leste asiático, atuaria com papel de "promotor e garantidor" de uma ampla unidade ocidental que contrabalançaria a ascensão chinesa. Sua preocupação passa por não permitir que a Rússia - principal potência terrestre, a partir do seu imperativo de expansão em busca do acesso aos mares quentes - busque alianças com potências do rimland asiático, sobretudo a principal potência em ascensão - a China. Essa situação geraria uma situação similar àquela temida por Mackinder, de uma aliança entre Rússia e Alemanha no início do século XX. Já na região da Ásia-Pacífico, os EUA deveriam estreitar a cooperação econômica e financeira com os países do Pacífico - Japão, Coreia do Sul, Filipinas, Singapura, Indonésia - a exemplo do que 
fez no Atlântico com a Inglaterra, a fim de manter a China no continente, dentro de uma ideia de unidade entre potências marítimas (IDEM, p. 170).

Nesse sentido, aparece novamente a preocupação a partir de uma visão geográfica e seus imperativos: a China, por se situar nas bordas da Eurásia e ser uma potência híbrida (terrestre e marítima) entra em colisão com os EUA ao se expandir. A China considera suas bordas marítimas como parte do seu entorno estratégico e um delicado problema de segurança: no século XIX e XX, foi porta de entrada dos invasores estrangeiros que impuseram contra ela o "Século de Humilhações". Além disso, o litoral não possui saída para os mares abertos, e é repleto de ilhas e países insulares, representando um permanente risco à sua segurança. Essas questões - históricas e geográficas - intensificam as disputas pelo controle dos mares que margeiam a China e colidem com o predomínio estadunidense no Pacífico, sendo o pano de fundo dos conflitos atuais no Mar do Sul da China ${ }^{6}$, além de gerar problemas com outros países da região. Brzezinski aponta, ainda, que os EUA deveriam atuar junto à Índia para auxiliar no equilíbrio regional e contrabalancear a China. Na Ásia, portanto, o estrategista defende um papel de "conciliador e balanceador", já que o equilíbrio na Ásia não pode ser imposto por uma potência externa e sua estabilidade não poderá se dar através de um poder concentrado chinês (BRZEZINSKI, 2012, p. 178).

Assim, contribuindo para o argumento central do artigo, a visão de Brzezinski é herdeira da geopolítica clássica de Mackinder e Spykman, apontando que no século XXI os EUA enfrentam o desafio de promover o equilíbrio de poder na Eurásia, em especial na região Ásia-Pacífico. Tal desafio impõe distintas e simultâneas preocupações com a ascensão da China, com a possibilidade de uma ameaça russa, e/ou com uma possível aliança sino-russa; além de ter que se preocupar com a possibilidade de erros de cálculos e rivalidades históricas por parte de aliados na região arrastarem os EUA para um conflito. Se, por um lado, desde o pensamento geopolítico clássico a Inglaterra e EUA podem observar a ascensão russa e/ou chinesa como ameaças; por outro lado, invertendo o ângulo, podemos recuperar a afirmação do geopolítico alemão Karl Haushofer (Apud MELLO, 1999) de que se deve "aprender com os inimigos" (assim como ele inverteu a teoria de

\footnotetext{
${ }^{6}$ Além do Mar do Sul da China, a expansão chinesa e a visão do seu entorno estratégico criam conflitos regionais permanentes com Japão, Coreia do Sul e com os países do Sudeste Asiático no Mar do Sul da China e no Mar do Leste.
} 
Mackinder) e "buscar aliados entre os adversários dos nossos inimigos", de forma pragmática - e não ideológica.

Olhando para a ação e documentos estratégicos dos EUA no pós Guerra Fria, é possível constatar que entre seus objetivos principais para manter a unipolaridade estavam: promover o equilíbrio e não deixar que nenhuma potência surja em nenhuma região do planeta; controlar territórios que sejam fontes ou rotas comerciais energéticas para auferir poder de barganha sobre aliados e poder de veto sobre rivais revelados e potenciais. Já nos documentos estratégicos do governo George H.W. Bush, de 1991, aparecia o objetivo de não deixar que Rússia retomasse sua militarização e o papel político da antiga URSS. A preocupação com a China - seu crescimento econômico e falta de transparência em gastos militares é lateral nos documentos estratégicos, até o governo Barack Obama, em 2009, quando há uma virada em relação ao foco no Oriente Médio presente no governo George Bush. Nos documentos estratégicos do governo Obama, dentro da política externa e de segurança voltada para a Ásia-Pacífico, há uma clara preocupação com a ascensão da China e com a retomada de uma política assertiva da Rússia e, mais que isso, com a aliança entre as duas e demais poderes "emergentes" (no BRICS, por exemplo), buscando tornar a distribuição de poder mais multipolar. A diretriz estratégica de contenção chinesa, e da aliança sino-russa, é clara. A forma de atuação (tática) pode ser mais ou menos explícita, afinal, desde os documentos de 1991, os EUA estabeleceram um discurso ético de promoção da democracia, liberdades e direitos humanos, ao mesmo tempo em que revelam uma preocupação central com a disputa de poder global (PADULA, 2018a). É interessante lembrar que Brzezinski (1986) recomendou a promoção de conturbações internas na URSS para que os EUA vencessem a Guerra Fria sem precisar incorrer em uma confrontação aberta e direta, que seria inconveniente para ambas superpotências com a paridade estratégica nuclear.

\section{A balança de poder de Raymond Aron}

O professor francês Raymond Aron (1905-1983), em sua obra "Paz e Guerra entre as Nações", publicada em 1962, define a balança de poder (a que ele se referia como "equilíbrio de forças") ${ }^{7}$ como derivada "da prudência necessária dos

\footnotetext{
7 "Acho preferível dizer "equilíbrio de forças" a "equilíbrio de poder, porque as forças são mais mensuráveis do que o poder ou a potência.” (ARON, 1979, p. 147).
} 
Estados desejosos de preservar sua independência, de não estar à mercê de outro Estado que disponha dos meios incontrastáveis." (ARON, 1979, p. 150). Assim, "todo Estado que quiser salvaguardar o equilíbrio, tomará posição contra o Estado ou a coalizão que pareça capaz de manter tal superioridade" (IDEM).

Para Aron, o equilíbrio não é uma imposição sistêmica nem algo prédeterminado, mas uma política que será adotada por cada Estado que, preocupado com a sua sobrevivência, buscará aumentar suas capacidades e mitigar ameaças, estabelecendo relações com outros Estados que 1) rejeitem a "monarquia universal" e 2) agreguem força para enfrentar um Estado mais forte. Para Aron, a noção de alianças e inimizades é essencialmente conjuntural dentro de um sistema que se pretenda multipolar, determinada pela relação de forças. (IDEM, p. 151). E essa conjuntura é constituída pelas relações de forças, inscritas num espaço histórico determinado, portanto, se modifica.

Assim, diferente dos autores discutidos na sessão anterior, que colocam os imperativos geopolíticos como razões de conflitos permanentes entre as nações, Aron, embora reconhecendo a influência da geografia, atribui peso maior aos fatores conjunturais da balança de poder.

as alegadas constantes, impostas pela geografia são enganosas. Não é a
geografia que sugere uma aliança ou uma inimizade, original ou
permanente, senão a projeção sobre o mapa de uma determinada relação
de forças: se essa relação evolui, outra política se apresenta como
razoável." (ARON, 1979, p. 123).

Ele argumenta que os fatores geográficos foram diminuídos pela capacidade humana de desenvolver tecnologias como a aeronáutica e as tecnologias nucleares. No que diz respeito às alianças e hostilidades duradouras, as oposições de interesses e as convergências de aspirações seriam suas causas primordiais. As alianças poderiam ser também determinadas por simples relação de forças ou por uma disputa em torno de um ponto definido (ARON, 2002, p. 158).

Essas explicações e razões de Aron à formação de alianças conjunturais podem ser perfeitamente compreendidas ao analisar a aproximação sino-americana na década de 1970, no contexto da Guerra Fria. Henry Kissinger utilizou-se delas para articular a aproximação sino-americana na década de 1970, em contraposição à União Soviética, no contexto da Guerra Fria. A China enxergava a URSS como principal ameaça à sua segurança devido aos contenciosos fronteiriços entre os dois. Já os EUA, desgastados na Ásia pela Guerra do Vietnã, viram na aproximação com a China a oportunidade a um só tempo de melhorar sua influência na Ásia, 
manter a neutralidade do gigante asiático e contrabalançar o próprio crescimento japonês.

Atualmente, as hostilidades representadas pela presença dos EUA na Eurásia convertem-se no fator primordial de aproximação sino-russa, potencialmente tornando-a uma "aliança duradoura", segundo os argumentos de Aron e, certamente, um pesadelo para o estrategista americano que operou a triangulação na década de 1970. Diferente de Brzezinski, que sugeriu a construção de um "Ocidente alargado", incluindo Rússia e Turquia, para contrabalancear o crescimento chinês, Kissinger (2016) argumenta que é preciso tratar a Rússia como uma grande potência e compreender e respeitar as diferenças geopolíticas e culturais constituintes daquele país. Para ele, a Rússia deveria ser percebida "como elemento essencial de qualquer novo equilíbrio global” (KISSINGER, 2016) e não como uma ameaça a priori aos Estados Unidos.

Tanto Brzezinski quanto Kissinger consideram a ascensão chinesa o maior desafio para a hegemonia dos EUA. Enquanto Kissinger (2016) propõe uma aproximação dos EUA com a Rússia para enquadrar a China, Brzezinski (2012) propõe o diálogo com a China e a incorporação da Rússia dentro da zona de influência ocidental, enquadrando-a à política e aos valores do "ocidente expandido", tornando-a parte do equilíbrio eurasiático, para contrabalançar a ascensão da China. Entretanto, a primazia estadunidense no pós-Guerra Fria resultou em uma postura hostil em relação à Rússia, que se manifestou em diversos momentos, tanto no campo militar, com a expansão da OTAN para o leste e com os projetos de instalação de escudos antimísseis no entorno russo; no campo "político-ético", em apoio às revoluções coloridas, quanto no campo da economia política, com a imposição de sanções, em especial após a crise com a Ucrânia em 2014. Diante das dificuldades encontradas no campo ocidental, a Rússia volta gradualmente sua diplomacia para o leste - em particular para a Ásia - visando atender ao seu interesse nacional e viabilizar seu desenvolvimento.

Da mesma forma, a notável ascensão relativa da China e uma sucessão de fatos relacionados à segurança movimentaram o debate acerca da atuação da política externa chinesa. Como pontuam Yan Xuetong (2014) e Wang Jisi (2011), a adoção do rebalanceamento estratégico da China no leste da Ásia pelos Estados Unidos (2010), as disputas nos Mares do Leste e do Sul da China com Japão, Filipinas e Vietnã; conflitos internos no Tibete (2008) e na província de Xinjiang (2009) e a escolha do Prêmio Nobel da Paz a Liu Xiaobo (2010); geraram intensos 
debates sobre qual deveria ser a estratégia internacional chinesa. $\mathrm{Na}$ década seguinte, as ações americanas como o lançamento do da Parceria Transpacífico, sucessivas ingerências no Mar do Sul da China, a prioridade estratégica para o IndoPacífico, além da "Guerra Comercial" e tecnológicas contra as empresas chinesas (em indústrias críticas para o poder militar), das investidas contra Hong Kong e Xinjiang explicitaram, aos olhos do governo, que trata-se de uma clara contenção ao desenvolvimento chinês e a seu papel cada vez mais influente na região e no mundo. As tensões sino-americanas e as necessidades do desenvolvimento chinês fazem emergir novas articulações regionais e globais.

Kenneth Waltz explica esse processo argumentando que à formação de um superpoder no Sistema Internacional tenderia a acelerar-se a formação de uma aliança contra balançante visando enfraquecê-lo relativamente, pois o Sistema tenderia ao equilíbrio (CEPIK, SCHNEIDER in MEDEIROS et al; 2010). Essa seria a situação dos EUA no pós-Guerra Fria (de superpoder, portanto desequilíbrio da balança), nas palavras de Waltz (2000):

Agora os Estados Unidos estão sozinhos no mundo. Assim como a natureza abomina o vácuo, a política internacional abomina o poder não balanceado. Frente ao poder não-balanceado, alguns Estados tentam aumentar sua própria força ou aliam-se com outros a fim de trazer a distribuição de poder global ao equilíbrio". (WALTZ, 2000, p. 28)

O poder não balanceado dos EUA e seus aliados passam a representar ameaças à segurança e ao desenvolvimento das chamadas "potências médias", sobretudo em um palco de interesse estratégico norte-americano: a Eurásia. Esse excedente de poder americano resultante da vitória na Guerra Fria passa a sofrer contestação cada vez mais intensa no século XXI, na busca de um mundo multipolar. No centro dessa articulação estão a Rússia e a China.

Interpretando Aron em sua teoria de equilíbrio de poder e formação de alianças, o que move a aproximação entre China e Rússia no início do século XXI não são apenas seus interesses econômicos strito sensu, ou conveniências pontuais. A convergência de aspirações relacionado ao desenvolvimento mútuo impulsiona o estabelecimento das relações e o início da cooperação. Entretanto, a ameaça comum representada pelo excedente de poder estadunidense projetado sobre a Eurásia alçará a parceria a um patamar superior, na sua segunda década, transformando-a em um forte instrumento contestador da ordem estabelecida no pós-Guerra Fria. Face a isso, a criação de um "espaço vital ótimo" para diminuir as vulnerabilidades regionais e melhorar as condições de segurança e 
desenvolvimento, e a posição relativa da China e da Rússia no Sistema Internacional, parece ser a tática compartilhada entre esses países.

Portanto, seja pela lente da geopolítica clássica anglo-saxã e seus herdeiros, seja através da visão de balança de poder de Aron ou Waltz, é possível compreender a busca dos EUA por manter sua posição de vantagem relativa de poder e atuação na Eurásia, assim como a busca de uma aliança compensadora por parte da China e da Rússia.

Desta forma, há a compreensão convergente por parte das autoridades chinesas e russas de que a multipolaridade depende de alinhamentos diplomáticos e da balança de poder regional, capazes de limitar a presença estadunidense, suas bases militares e que possam fornecer maior autonomia aos países da região para tratar dos seus problemas internos. O caminho que os governos encontraram para responder a esse desafio é unir esforços em torno da diminuição da vulnerabilidade material dos países em relação a temas estratégicos, através da cooperação bilateral e o fortalecimento regional, através da integração da Eurásia.

Veremos, nas próximas sessões, como essas relações se materializam em termos de cooperação energética, na Ásia Central - entorno estratégico comum, e no esforço de integração eurasiático.

\section{Cooperação Energética Sino-Russa}

A Rússia possui a segunda maior produção de gás e a terceira maior produção de petróleo do planeta (BP, 2020). A China tornou-se a maior importadora mundial de petróleo em 2017. Há, portanto uma evidente complementariedade energética entre os dois países, conforme tabela 1, suficientes para justificar uma ampla cooperação na área. Entre os anos de 2014 e 2019, as exportações de petróleo russo à China cresceu de 33,1 milhões de toneladas para 77,7 milhões de toneladas (BP, 2020), tornando a Rússia a maior fornecedora de óleo cru para a China. Esse crescimento exponencial se deu, sobretudo, como parte de uma política estratégica para o setor, por parte dos dois países (RIAC, 2020). ${ }^{8}$

Tabela 1-Complementariedade energética Sino-Russa

\begin{tabular}{|c|c|c|c|c|}
\hline Ano 2019 & $\begin{array}{l}\text { Produção de } \\
\text { Petróleo } \\
\text { (Milhares de } \\
\text { barris/dia) }\end{array}$ & $\begin{array}{l}\text { Produção de } \\
\text { Gás Natural } \\
\text { (bilhões } \\
\mathrm{m}^{3} / \text { dia) }\end{array}$ & $\begin{array}{l}\text { Consumo } \\
\text { Petróleo } \\
\text { (milhares de } \\
\text { barris/dia) }\end{array}$ & $\begin{array}{l}\text { Consumo Gás } \\
\text { Natural } \\
\text { (bilhões } \mathrm{m}^{3} \\
\text { barris/dia) }\end{array}$ \\
\hline
\end{tabular}

8 Disponível em https://russiancouncil.ru/papers/Russia-China-2020-Report58-En.pdf 


\begin{tabular}{|l|l|l|l|l|}
\hline China & 3.805 & 679,0 & 14.056 & 444,3 \\
\hline Rússia & 11.540 & 177,6 & 3.317 & 307,3 \\
\hline
\end{tabular}

Fonte: elaboração própria, com dados da BP Statistical 2020

Por razões geoestratégicas, a cooperação entre esses países vai muito além da complementariedade. O principal fator aqui refere-se à chamada geopolítica dos dutos na Eurásia, que envolve disputa pelos recursos energéticos regionais, que não se resume à articulação entre importantes atores regionais, mas também com a participação de atores externos. Por um lado, temos grandes demandantes como China, Índia, Japão, Coreia do Sul e países da Europa Ocidental (como Alemanha e França). Por outro lado, grandes produtores como Rússia, Irã, Cazaquistão, Azerbaijão e Turcomenistão. Ainda, temos países importantes para rotas comerciais, como a Geórgia e a Turquia. Vale destacar também a atuação dos EUA buscando controlar os territórios importantes em termos de recursos e rotas comerciais energéticas como instrumento de poder dos EUA, para ter poder de barganha sobre aliados ou de veto sobre rivais. Assim, a articulação terrestre entre países da região, em particular entre Rússia e China, mas também com Irã e Turcomenistão, visa diminuir a interferência ocidental decorrente do controle de dutos terrestres e dos principais pontos de passagem marinhos (PADULA, 2018a). O mapa da figura 1 mostra a concentração dos fluxos marinhos e a importância dos Estreitos de Ormuz e Malaca para a segurança energética chinesa.

Figura 1- Principais fluxos de petróleo 2019 (em milhões de toneladas)

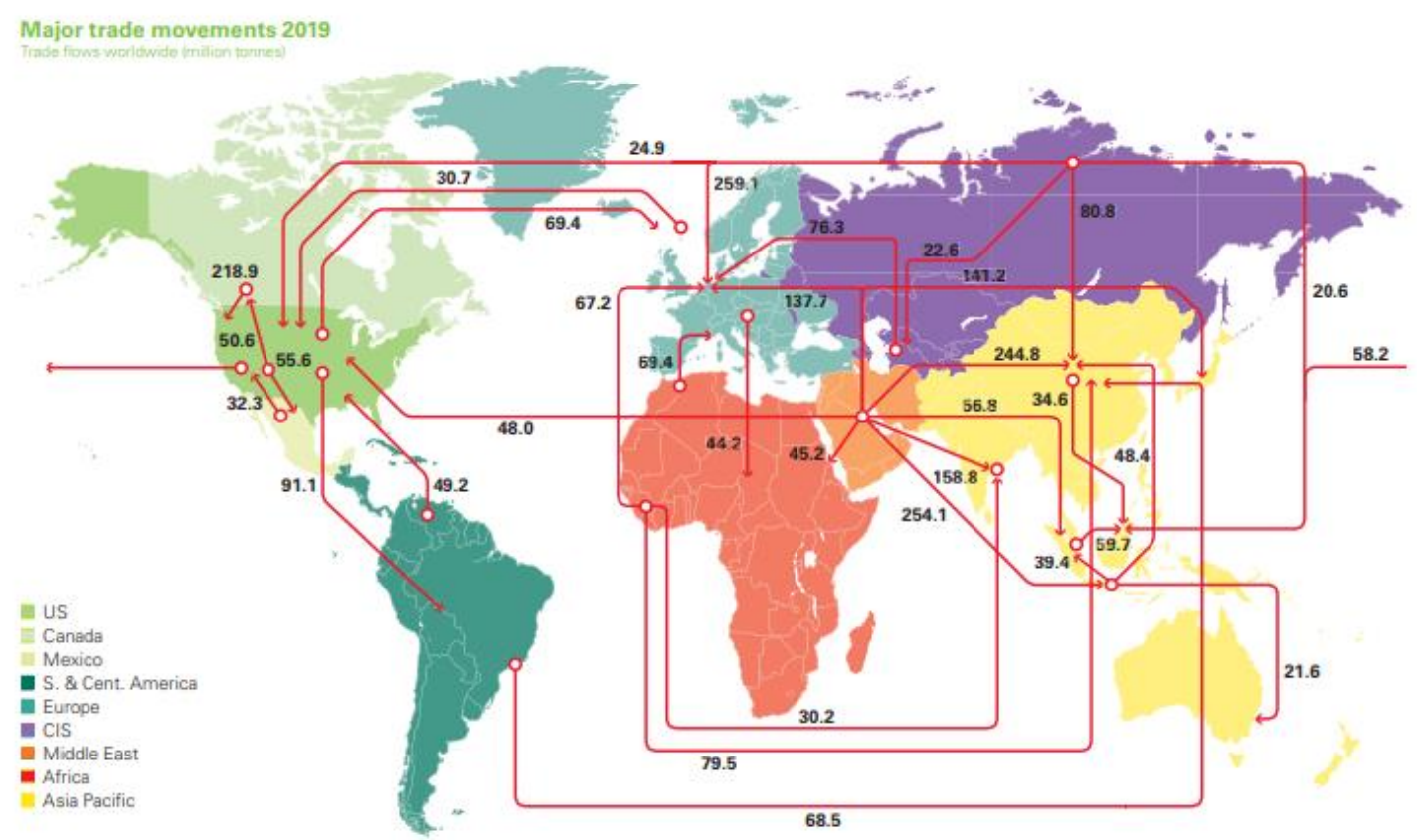


Fonte: BP Statistical 2020

Outra forma do poder americano instrumentalizar os recursos energéticos para enfraquecer rivais dependentes da exportação desses recursos é atuando para influenciar o preço do petróleo. Ao reduzir a importação americana por conta do aumento da produção interna, cai a demanda internacional por petróleo. Se não for possível um acordo para reduzir a produção no âmbito da OPEP (Organização dos Países Produtores de Petróleo), especialmente por conta da postura de aliados estratégicos dos EUA como a Arábia Saudita, haverá um aumento da quantidade de petróleo disponível no mercado, exercendo forte pressão para baixo sobre os preços, fazendo despencar as receitas dos países exportadores. De acordo com Padula (2018b), esse processo derrubou o preço do petróleo no mercado internacional em 2014, impactando na receita de Estados rivais que são dependentes da exportação, como é o caso da Rússia.

As sanções americanas aplicadas sobre o Irã, país com amplas reservas de petróleo, barraram as exportações em dólar neste país, mas acabaram impulsionando uma maior parceria deste com China e Rússia ${ }^{9}$, realizando contratos autônomos na moeda chinesa e através de contratos de futuro de petróleo vinculados aos investimentos chineses em infraestrutura no país, dentro do escopo da Nova Rota da Seda (ALVARES, 2020).

Os recursos energéticos russos são centrais para o desenvolvimento nacional e são frequentemente utilizados como arma em embates geopolíticos. A Europa é a maior compradora dos recursos russos ${ }^{10}$, o que representa um fator de vulnerabilidade para auferir receitas, razão pela qual as autoridades russas buscam ampliar sua participação no mercado do leste asiático. Importantes acordos já vinham sendo firmados no sentido de garantir maior participação chinesa na exportação de energia russa, sobretudo no que tange à ampliação de infraestrutura (dutos) conectando a Ásia e o Oceano Pacífico (inclusive no sentido de prover energia a outros países asiáticos, como Japão e Coreia). Como parte desse projeto, foi inaugurado em 2009 o porto petrolífero de Kozmino (dentro do complexo de Vostochnyy), para onde se destina o oleoduto Sibéria Oriental-Oceano Pacífico (IDEM).

\footnotetext{
${ }^{9}$ Sobre a cooperação financeira sino-russa ver ALVARES, 2020.

${ }^{10}$ A Rússia exportou 188 bilhões de $\mathrm{m}^{3}$ de gás natural para a Europa em 2019 por meio de gasodutos, de um total de 217,2 bilhões de $\mathrm{m}^{3}$ exportados pela Rússia, representando $86,5 \%$ (BP Statistical, 2020)
} 
Visando diversificar seus fluxos energéticos, e nos marcos dos projetos da Nova Rota da Seda, a parceria energética deu um salto. Em maio de 2014, as estatais russa e chinesa - Gazprom e CNPC, respectivamente - firmaram acordos com duração de 30 anos para a construção do gasoduto "Potência da Sibéria"11. O gasoduto, que foi inaugurado em dezembro de 2019, tem extensão inicial de 3 mil quilômetros e capacidade prevista de fornecimento de 38 bilhões $/ \mathrm{m}^{3}$ por ano para a China. O projeto prevê a extensão até Kabavarosk, a partir de onde será conectado a uma rede já existente até o porto de Vladivostok, atingindo um volume transportado de 61 bilhões $/ \mathrm{m}^{3}$ e uma extensão de aproximadamente 4 mil quilômetros. Também está previsto um gasoduto "Potência da Sibéria 2", em direção oeste, mas ainda não teve suas obras iniciadas.

Além do "Power of Siberia", dois outros projetos na área que contaram com grande aporte chinês chamam atenção: o Yamal LNG e o Artic LNG 2. O pretende alcançar uma produção de 16,5 milhões de toneladas por ano de gás natural liquefeito e já está em funcionamento desde $2017^{12}$. O segundo tem seu campo de extração localizado na Península de Guyan, no norte da Sibéria, já recebeu de bancos chineses US $\$ 12$ bilhões em empréstimos e terá capacidade de produção de 18,9 milhões de toneladas por ano de gás liquefeito ${ }^{13}$. Ambos projetos apontam para o potencial de desenvolvimento conjunto na produção e exploração de óleo e gás e o desenvolvimento da Rota Marítima do Norte, que pretende ligar o noroeste europeu ao Estreito de Bering, através do Ártico, através das águas pertencentes à Rússia, um projeto com forte componente geopolítico e de segurança nacional, para além dos interesses comerciais (ALVARES, 2020).

O aumento exponencial da cooperação energética entre os dois países nos últimos anos se dá a partir de um diagnóstico estratégico comum de vulnerabilidade diante das Potências ocidentais - seja pelos destinos de exportação, no caso russo, seja pelo controle dos mares e dos estreitos por onde passam as importações, no caso chinês. Como demonstrado, o aprofundamento da relação não se dá apenas com o aumento das trocas entre os dois países, mas sobretudo na tentativa de constituir uma nova articulação para os fluxos, envolvendo atores relevantes eurasiáticos: produtores, consumidores e corredores energéticos terrestres. Conectando ao argumento central do artigo, a atuação permanente dos EUA e seus

\footnotetext{
11 Power of Siberia, em inglês.

${ }^{12}$ de acordo com o site oficial do projeto http://yamallng.ru/en/

${ }^{13}$ Cf. informações do site da Novatek, disponível em http://www.novatek.ru/en/business/arctic-Ing/
} 
aliados ocidentais na região, em sua busca por manutenção de uma vantagem relativa de poder favorável e, portanto, cerceando a capacidade de expansão e autonomia da Rússia e da China, justificam sua aproximação e cooperação estratégica energética, assim como articulações com demais países da região. Como pano de fundo temos a geopolítica dos dutos e dos mares, mas sobretudo as balanças de poder regional e global.

\section{Ásia Central: entre o balanceamento e a divisão de trabalho}

A Ásia central é um ponto nevrálgico para as diplomacias russa e chinesa, considerado por ambos parte de seus entornos estratégicos. Por sua localização central continental, foi ocupada por distintos povos e representa um elo físico e cultural entre o ocidente e o oriente. Por ser dotada de recursos estratégicos e por influenciar na balança asiática e do Oriente Médio, tem sido historicamente alvo de cobiça das grandes potências, arbitrando inclusive na formação de fronteiras artificias, gerando profundas instabilidades políticas, étnicas e econômicas que contribuem para o fortalecimento de determinadas minorias, forças separatistas e grupos terroristas.

Rússia e China percebem esses problemas presentes nos países da Ásia Central como a extensão dos seus próprios problemas de segurança. Ou seja, instabilidades relacionadas com o chamado "três males" - separatismo, extremismo e terrorismo - podem transbordar fronteiras e tornarem-se problemas de segurança interna. Por essa razão, a Ásia Central também foi precursora de uma iniciativa regional envolvendo Rússia e China: o Grupo dos Cinco de Xangai, em 1996, embrião da OCX (2001).

A China enfrenta sucessivos problemas separatistas e de terrorismo no oeste do país, sobretudo na província de Xinjiang, que faz fronteira com Cazaquistão, Quirguistão e Tadjiquistão. Para enfrentar o problema, o governo elegeu a região como hub do cinturão terrestre do projeto Belt and Road Initiativa (BRI), a fim de promover crescimento econômico, estabilidade política e afastar os "três males", não apenas dentro do território chinês, mas também em acordos com os governos da Ásia Central. Dos seis corredores da Nova Rota da Seda, três partem de lá e atravessam os países da Ásia Central.

Além disso, por ser dotada de recursos energéticos e por suas características geográficas centrais, o projeto na região cumpre um objetivo primordial de conectar 
o Oriente Médio, a Europa e o Mar da Arábia, através de corredores terrestre para fluxo energético (conforme o mapa da figura 1, na seção anterior), de alimentos e matérias-primas, diminuindo a dependência chinesa das passagens marítimas (estreitos ou chokepoints) dominados pelo poder marítimo americano e seus aliados.

A Rússia tem influência histórica sobre a Ásia Central, que fez parte do domínio do Império Russo e posteriormente integrou a União Soviética. Assim como para Moscou, a desintegração da URSS impôs uma severa crise econômica aos países e criou um vácuo de poder, aumentando as instabilidades e disputas locais, assim como o assédio de potências externas, como os EUA e aliados ocidentais. Por questões securitárias e estratégicas, mas também de identidade cultural, a Rússia mantém importante presença na região, através de relações próximas com os governos e do estabelecimento de iniciativas como a Comunidade dos Estados Independentes e da União Econômicas Eurasiática, além da OCX.

Ao contrário do que representou a presença dos EUA no Afeganistão, amadurece entre as lideranças chinesas e russas a necessidade de priorizar a reconstrução econômica e o desenvolvimento dos países centro-asiáticos (PAUTASSO, 2011). Esse tema é recorrentemente abordado pelo corpo diplomático chinês em suas entrevistas à imprensa, tanto no escopo da OCX, quanto da parceria com a Rússia. Injetar investimento, construir infraestrutura, afastar a presença de potências extrarregionais e estabilizar a região, afastando os "três males" são prioridades na agenda de integração regional, preocupações comuns dos chineses e dos russos.

Entretanto, Moscou vive um dilema: sabe da importância dos investimentos chineses para o desenvolvimento dos países da Ásia Central, mas teme que Pequim ocupe um papel historicamente ocupado pelos russos. Ao mesmo tempo, os dois países sabem que as instabilidades políticas, sociais e de segurança podem criar fortes riscos e/ou inviabilizar os investimentos chineses.

Ao fomentar a integração entre a União Econômica Eurasiática e a Nova Rota da Seda, ao invés de tentar conter tal iniciativa, a Rússia auxilia e aprofunda as possibilidades chinesas na região, visando auxiliar, mediar e influenciar na escolha dos projetos e beneficiar-se do desenvolvimento. Dada à proximidade física e cultural, a Rússia enxerga que instabilidades na Ásia Central podem rapidamente migrar para o seu território e converterem-se em movimentos anti-Rússia. Assim, compreende que levar desenvolvimento e diminuir as vulnerabilidades dos países do seu entorno significa um aumento da sua própria estabilidade e segurança. 
Dessa maneira, a parceria sino-russa na Ásia Central constitui uma certa "divisão de trabalho" (GABUEV, SPIVAK; 2019). Nela, a China entra com o financiamento dos projetos e a Rússia auxilia na articulação dos mesmos junto aos países e provê segurança em áreas de maiores instabilidades, sendo, portanto, uma "gestão compartilhada", considerando a possibilidade de um jogo de soma positiva, mesmo havendo riscos e, em especial, levando em conta aquilo que consideram uma ameaça maior. Partindo-se do "laboratório" centro-asiático e da divisão de tarefas nele estabelecido, e diante da ameaça representada pela presença de potências extrarregionais, os dois países buscam construir um novo equilíbrio intrarregional, chamado de integração da Eurásia.

\section{Parceria Sino-Russa e a integração da Eurásia}

Como vimos na primeira seção, as teorias geopolíticas clássicas colocam a Eurásia como continente basilar, tanto por razões geográficas quanto materiais. Novamente, na atualidade, podemos enxergar a sua centralidade na competição geoestratégica entre o poder terrestre e marítimo, como resultado da ação das forças centrífugas (Rússia) e centrípetas (Estados Unidos e Aliados) (TEIXEIRA JUNIOR, 2018), e da China, como potência do rimland, tentando unificar a Eurásia da borda para dentro, em aliança com a potência terrestre.

Na seção anterior, a partir da concepção de Raymond Aron, apresentamos as alianças entre países como sendo essencialmente conjunturais, determinadas pelas políticas dos Estados olhando para a distribuição de poder global e guiadas pela busca do equilíbrio de poder. Nesse sentido, a parceria sino-russa atual, para além de objetivos específicos, está situada dentro de uma razão estrutural da ordem: alterar a balança de poder internacional, no sentido de contrabalançar o excedente de poder unipolar dos EUA conquistado com o fim da Guerra Fria, sendo, portanto, contestadora da ordem global.

Pela importância da Eurásia, essa contestação se materializa, sobretudo, em diminuir a presença estadunidense na região. Em contraponto à ideia de "ocidente expandido" de Brzezinski (2012), ou de minar a ascensão de potências regionais de Mearsheimer (2001), Rússia e China compartilham a ideia de integração eurasiática. Essa visão, surge a partir da compreensão de uma ameaça comum e das dificuldades de enfrentá-la unilateralmente. As ameaças se manifestam, no entanto, de diferentes formas e intensidades para as diferentes potências, de acordo com a 
grande estratégia que os EUA perseguem em busca da hegemonia (MARTINS, CEPIK; 2014), utilizando-se da presença militar e de uma rede de aliados permanentes (BRITTES, 2016; BREZINSKI, 2012; PADULA, 2018a). Assim, cada país, buscando seu interesse nacional, buscará dar respostas à essas ameaças.

Para a China, o lançamento da estratégia americana do pivô asiático pelo presidente Barack Obama em 2010, representou uma clara tentativa de contenção ao seu crescimento, em termos econômicos (com o lançamento da Parceria Transpacífico), militares (com aumento da presença nos mares do Sul e do Leste da China) e institucionais, buscando esvaziar os fóruns liderados pela China (BRITTES, 2016). O lançamento da BRI, em 2013 pelo Presidente Xi Jinping, pode ser interpretado como uma reação à ameaça representada pelo novo "pivô asiático" americano. De acordo com a tradição da visão "Tianxia" (holística) chinesa, o projeto responde a um só tempo aos desafios internos, levando desenvolvimento e estabilidade ao oeste chinês e geopolíticos, a partir das suas características de potência híbrida, com amplos investimentos em infraestrutura por terra, portos e mar, conforme o mapa da figura 2, utilizando-se da geoeconomia para melhorar sua influência regional e global, e reduzir suas vulnerabilidades.

Figura 2- Traçados do Projeto da Iniciativa Cinturão e Rota

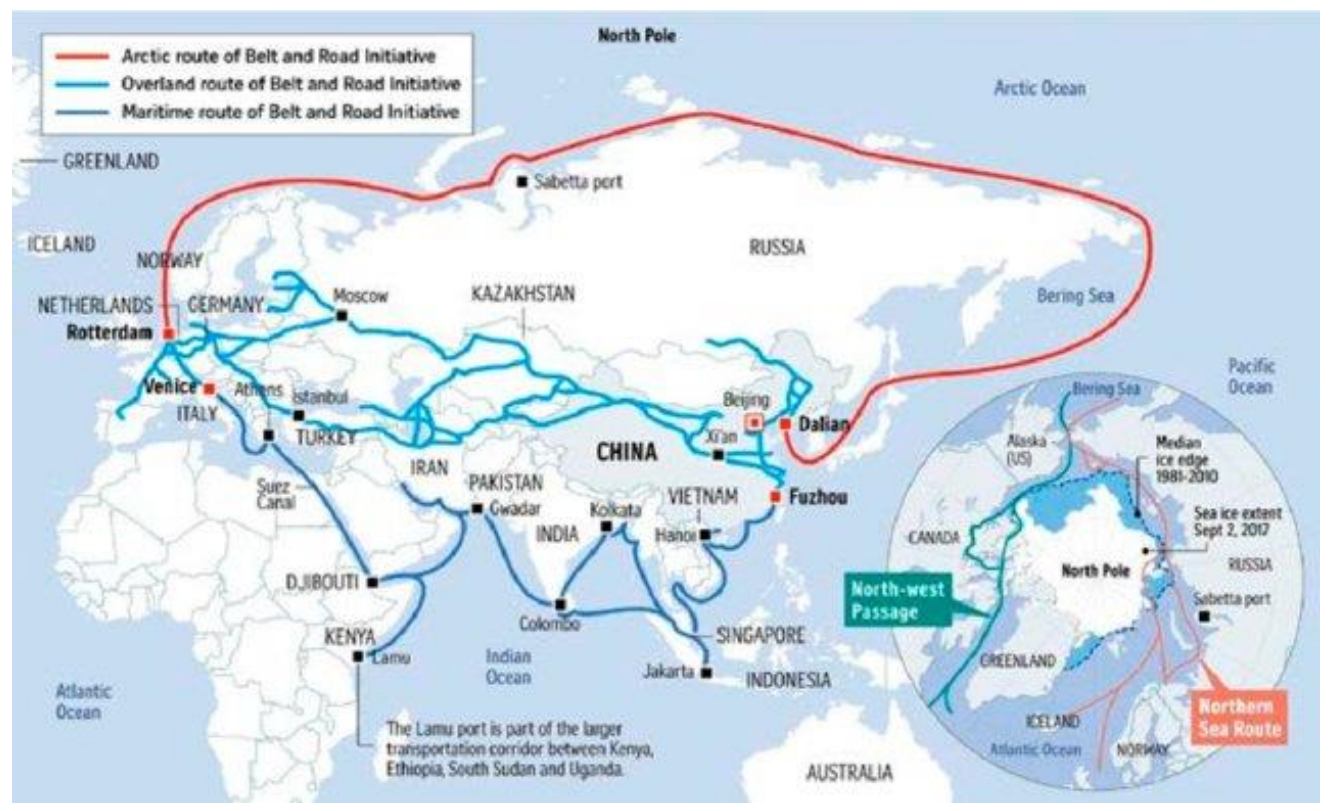

Fonte: Duchâtel \& Sheldon-Duplaix, $2018^{14}$

\footnotetext{
${ }^{14}$ Disponível em https://www.researchgate.net/figure/Belt-and-Road-Initiative-map-Duchatel-SheldonDuplaix-2018 fig1 336616579
} 
Para a Rússia, o lançamento da BRI foi visto como risco e oportunidade. De um lado, o crescimento da influência chinesa sobre a Ásia poderia deslocar a Rússia de sua esfera de influência tradicional. De outro, a deterioração das relações com o Ocidente, em especial após as sanções de 2014, fizeram com que a política externa se voltasse mais em direção à Ásia e aumentasse a cooperação com a China e outros parceiros, representando uma miríade de oportunidades, devido à complementariedade econômica e ao grande mercado asiático. Segundo Pautasso (2011), "o sofisticado nexo regional-global explica-se por agregação de poder e projeção internacional, por balanças de poder (intra/inter) regionais, por crises e inseguranças regionais por processos de integração econômico-social mais densos" (PAUTASSO, 2011, p. 156; HURREL, 2009).

A Rússia organizou, em 2014, a partir de iniciativas anteriores, a União Econômica da Eurásia (UEE), reunindo além dela, Bielorússia, Quirguistão, Cazaquistão e Armênia. Com isso, o país conseguiu ampliar sua interlocução com a China em todos os aspectos, em especial na consecução da BRI. Esse foi o embrião de uma visão coordenada entre os distintos blocos na Eurásia, fazendo emergir a ideia de Grande Eurásia, ou Grande Eurásia Expandida ${ }^{15}$. De fato, a Rússia cumpre um importante papel na viabilização da BRI, promovendo a ideia de uma "rede de integração", que tem na China o maior líder econômico e na Rússia um parceiro provedor de segurança e que suaviza desconfianças regionais, sob a ideia de integração eurasiática. Assim, a Rússia promove, ao envolver instituições regionais, uma espécie de "balanceamento brando"16 (DIESEN, 2017) em relação à China, fazendo um jogo de soma positiva, ao mesmo tempo que se une a ela para fortalecer a integração e o desenvolvimento regionais, visando contrabalancear a presença americana na Eurásia.

Trata-se de uma série de arranjos intrarregionais visando o desenvolvimento e a segurança nacionais e a necessidade de constituição de um espaço integrado

\footnotetext{
${ }^{15}$ A ideia de "Greater Eurasia", ou "Greater Eurasian Partnership" surgiu pelos think tanks russos no ano de 2015. A ideia era a união dos projetos da UEE e da BRI e foi formalmente acordada entre Putin e Xi Jinping em 2016, quando assinaram um memorando de intenções.

${ }^{16}$ Segundo Hurrell (2009), o balanceamento brando não envolve tentativas diretas de confrontar ou constranger o país dominante por meio de alianças militares (balanceamento externo) ou mobilização militar (balanceamento interno). Ao contrário (...) envolve outras formas de cooperação: ententes, entendimentos informais, exercícios cooperativos ad hoc ou colaboração em instituições regionais ou internacionais. O propósito dessas formas cooperativas é complicar e aumentar os custos das políticas norteamericanas em instituições internacionais (especialmente negando legitimidade a elas), desafiar preferências norte-americanas dominantes e negar cooperação efetiva (em contraste com cooperação formal ou retórica) da qual depende o cumprimento dos objetivos de política externa dos Estados Unidos (HURREL, 2009, p. 34).
} 
eurasiático em contraposição à presença extrarregional, sem o predomínio, no entanto, de uma única potência. A compreensão é de que, por um lado há a necessidade do financiamento chinês, por outro, a proteção dos interesses nacionais em um formato coletivo de diálogo com a China para estabelecer os projetos da BRI seria mais efetiva do que em nível bilateral (TSVYK, 2018), dada a assimetria econômica do dragão asiático em relação aos vizinhos. Ao invés de negociarem individualmente, as organizações regionais cumprem esse papel, através da OCX, da ASEAN, da UEE, dos BRICS, dos RICS, etc.

Como base institucional mais consolidada para a ideia da "Grande Eurásia" está a Organização para Cooperação de Xangai (OCX), criada em 2001, com origem no Grupo dos Cinco de Xangai (1996), como apontado acima. A OCX foi então fundada por China, Cazaquistão, Quirguistão, Rússia, Tadjiquistão e Uzbequistão - tendo Irã e Mongólia como membros observadores. Articulada inicialmente por motivação securitária contra o terrorismo, separatismo e extremismo, sua importância e seu escopo de atuação foram crescendo à luz dos acontecimentos da primeira década do século XXI. De um lado os atentados de 11 de setembro de 2001 colocaram a Organização em colaboração com os EUA. De outro, cresceu a presença estrangeira na Ásia Central, fruto da presença militar ocidental no Afeganistão, aumentando as instabilidades regionais.

Essa percepção fez com que a atuação regionalista via OCX fosse crescendo, ligando a ideia de segurança e combate às instabilidades à ideia do desenvolvimento regional e a ameaças vindas da atuação de potências extrarregionais. A OCX passou desenvolver um claro antagonismo à OTAN e a envolver acordos de cooperação e manobras militares (incluindo guerra cibernética e informacional), cooperação econômica e cultural, e uma série de grandes projetos de transportes, energia e telecomunicações. No campo econômico vem discutindo arranjos comerciais-financeiros fora do dólar e a formação de um cartel de gás natural. Assim, uma articulação política robusta envolvendo China e Rússia (e agora possivelmente Índia, e quem sabe no futuro Irã) formando uma coalizão anti-OTAN, anti-EUA e anti-Ocidente, vem se desenvolvendo no grande jogo da Eurásia.

A cúpula de 2005 é um marco de mudança de postura da OCX em relação à presença americana na região, denunciando o unilateralismo e a interferência externa nos assuntos domésticos de Estados Soberanos (OCX, 2005). A mesma reunião aprovou a entrada como observadores do Irã, Paquistão e Índia e rechaçou a participação dos EUA na mesma condição (ALVARES, 2020). As cúpulas de 2005 
e 2006 marcam uma posição contestadora da Organização em relação aos EUA, de um lado através da defesa da multipolaridade e da denúncia da presença estrangeira e, de outro, propondo um novo modo de relacionamento entre as nações (cooperação Sul-Sul), através da coordenação e atuação conjunta de distintas iniciativas de integração regional, como a ASEAN, a EURASEC e a CEI (OCX, 2006; apud ALVARES 2020), constituindo uma visão embrionária da integração eurasiática. Em 2005, a OCX apontou como prioridade os projetos energéticos conjuntos, e em 2006 foi criada uma associação interbancária para reunir fundos para os projetos, tendo a China como principal patrocinadora. É importante notar que essas iniciativas estão no âmbito de uma visão estratégica mais ampla sobre a questão energética e a geopolítica dos dutos na Eurásia, assim como do poder financeiro auferido pelos EUA como emissor da moeda internacional e centro controlador de fluxos financeiros internacionais.

Essa evolução, somada à crise econômica mundial e ao aumento relativo do papel dos chamados "países emergentes", criaram as condições para uma atuação mais ampla e influente da OCX na sua segunda década. Suas reuniões de cúpula estimulam o desenvolvimento regional, a integração física, a articulação entre as iniciativas regionais existentes e a cooperação prática nas mais diversas áreas. Ao mesmo tempo, reforçam o princípio da autonomia regional e os vínculos práticos estabelecidos entre os países, ao repudiar o unilateralismo, as agressões e interferências externas e a promoção de regime changes (em especial no contexto das "Primaveras Árabes") (OCX, 2011, 2012), os confrontos militares (na Líbia e na Síria) e o caráter desestabilizador das ações unilaterais e de interferência à soberania e integridade territorial de outros países (ALVARES, 2020). A inclusão das duas potências nucleares - Índia e Paquistão - em 2017 (já aprovadas em 2015), como membros permanentes, fruto da articulação russa e chinesa, respectivamente, significaram um importante salto, uma vez que inclui a relutante Índia dentro do mais institucionalizado processo de integração eurasiático, apesar da sua conhecida diplomacia pendular. Às vésperas de completar duas décadas, a OCX tem presença na Europa Oriental, Oriente Médio, Sul da Ásia, Leste Asiático e Ásia Central. Representa $40 \%$ da população global e mais de $20 \%$ da economia. Possui cooperação com os mais importantes mecanismos multilaterais presentes na Eurásia.

A criação de parcerias regionais é uma maneira de reduzir as incertezas e instabilidades do cenário internacional. Para as políticas externas russa e chinesa, é 
também uma maneira de reduzir os desequilíbrios e viabilizar projetos em busca de modernização e desenvolvimento regionais, que também contribuem para prover segurança para seus projetos nacionais. Por isso, o processo de integração eurasiática tem sido construído sob liderança sino-russa e é resultado do aprofundamento desta parceria, devido à visão comum da balança de poder internacional e da centralidade da Eurásia.

\section{Considerações Finais}

Neste artigo, vimos como a geopolítica clássica anglo-saxã aponta a Eurásia como continente central na disputa de poder global e coloca aos EUA o imperativo estratégico de promover o equilíbrio de poder no continente. Portanto, os EUA devem atuar de forma contrária à ascensão de qualquer potência ou aliança no continente, como de fato é revelado na sua estratégia pós Guerra Fria. Além da preocupação permanente com a Rússia desde o fim da Guerra Fria, os documentos estratégicos dos EUA apontam no século XXI uma preocupação com a ascensão da China e, ainda, com a aproximação sino-russa, como uma ameaça ao objetivo estadunidense de manter uma ordem unipolar.

As mudanças no cenário internacional e o aumento das rivalidades interestatais esquentaram a disputa pelo domínio político do chamado continente basilar no primeiro quarto do século XXI. Os EUA atuam para não permitir que nenhum país controle aquele território, enquanto China e Rússia se unem para diminuir a interferência externa na região. A integração regional e a coordenação entre as distintas iniciativas passam a cumprir esse papel estratégico, carregando consigo um forte caráter revisionista.

Apesar disso, as alterações na balança de poder internacional e as hostilidades intra e extrarregionais irão determinar a durabilidade e a intensidade dessa parceria no futuro. Um crescimento desproporcional do poder chinês sobre a região, ou um processo de divisão interna podem criar dificuldade para a evolução da parceria. O mais provável é que dentro das disputas entre China e EUA, esses tentem atrair aliados a fim de enfraquecer o processo de integração regional e/ou desestabilizar países que fazem parte do condomínio de coordenação sino-russa.

Atenção especial deve ser dispendida ao papel da Índia e da Europa ocidental dentro do cenário de transição da ordem. A primeira tem atuação pendular e busca trabalhar em uma relação de unidade e luta com ambos os "blocos", buscando se 
fortalecer relativamente. Suas rivalidades geográficas com a China e o aumento do poder do vizinho são preocupações permanentes. Entretanto, o aprofundamento da integração eurasiática sob liderança sino-russa sem a sua participação acaba isolando-a regionalmente e impondo riscos ainda maiores.

Já a União Europeia se vê mergulhada em uma crise econômica e de identidade, além de estarem presas à tutela militar dos EUA na OTAN. A Europa, promotora da ordem mundial nos últimos séculos se veem em outro tipo de dilema: incorporar-se ao processo de construção da Grande Eurásia e beneficiar-se financeiramente do mesmo ou preservar-se enquanto bastião dos valores do ocidente no Velho Continente, mantendo uma estratégia "associada" em relação à potência hegemônica e contribuindo para manutenção da ordem.

Os presidentes Xi Jinping e Vladimir Putin anunciaram a "parceria sem precedentes" no ano de 2019, rebatizando-a enquanto "Parceria abrangente para uma Nova Era". Esse artigo buscou argumentar que o que a alçou a esse novo patamar foram menos os interesses específicos econômicos e mais a visão próxima com relação aos desafios geopolíticos e da balança de poder, com centralidade para o papel da Eurásia. Embora haja desconfianças mútuas quanto às desavenças históricas, características geográficas e assimetria de poder, e elas façam parte do cálculo na tomada de decisões dos dois governos, a percepção da ameaça comum do excedente de poder americano que se projeta na Eurásia é a bússola dessa nova fase da cooperação.

\section{REFERÊNCIAS}

ALVARES, T. Rússia e China: uma parceria estratégica pela multipolaridade. Dissertação de Mestrado, PEPI-UFRJ, 2020.

ARON, R. (1962). Paz e Guerra entre as Nações. Editora Universidade de Brasília, Brasília, 1979, 708p.

BP 2020. Statistical Review of World Energy 2020. Edição 69, disponível em https://www.bp.com/content/dam/bp/business-sites/en/global/corporate/pdfs/energyeconomics/statistical-review/bp-stats-review-2020-full-report.pdf

BRITTES, P.V.P. A Política dos EUA para o Leste Asiático no Governo Obama: o balanceamento da China e a geopolítica regional. Revista OIKOS | Rio de Janeiro | Volume 15, n², 2016, disponível em http://www.revistaoikos.org/seer/index.php/oikos

BRZEZINSKI, Z. Strategic Vision. America and the crisis of Global Power. New York: Basic Books, 2012.

BRZEZINSKI, Z. Game Plan. Atlantic Monthly Press, 1986. 
CEPIK, M.; SCHNEIDER, L. Kenneth Waltz. In MEDEIROS, M.A; LIMA M.C; VILLA, R.; REIS, R. R. Clássicos das Relações Internacionais. Editora Hucitec, 2010, disponível em http://professor.ufrgs.br/marcocepik/files/cepik schneider 2010 kenneth waltz 1.pdf

DIESEN, G. Russia, China and the "balance of dependence" in Greater Eurasia. Valdai Papers, 2017, disponível em https://eng.globalaffairs.ru/articles/russia-china-and-balance-ofdependence-in-greater-eurasia/\# ftnref3

EDER, T.S. China - Russia Relations in Central Asia: Energy Policy, Beijing's New Assertiveness and 21st Century Geopolitics. Springer VS, 2014.

FIORI, J. L. Sobre a Guerra. Editora Vozes, Rio de Janeiro, 2018.

GABUEV, A; SPIVAK, V. The Sino-Russian Entente. Carnegie Moskow Center, 2019, disponível em https://carnegie.ru/specialprojects/sinorussianentente?lang=en, acesso em 18 de outubro de 2019.

GAROUSOVA, L. 2014. "Mejdounarodnaya migratsiya v sovremennoï Rossii: Dalnevostotchnyï kontekst" (International migration in Russia today: the context of the Russia Far East)." Territoriya novikh vozmojnosteï (The land of new opportunities) 27(4): 922

HURRELL, A. Hegemonia, liberalismo e Ordem Global: Qual o Espaço para Potências Emergentes? Editora FGV, Rio de Janeiro, 2009, 168p.

KAPLAN, R. The Quiet Rivarly Between China and Russia. The New York Times, 3 de novembro de 2017, disponível em https://www.nytimes.com/2017/11/03/opinion/china-russiarivalry.html

KISSINGER, H. (2014). A Ordem Mundial. Editora Objetiva, 2015.

KISSINGER, H. Kissinger's vision on US-Russia Relations (Kissinger's speech in Moscow). The National Interest, February 04, 2016. Disponível em: http://nationalinterest.org/feature/kissingers-vision-us-russia-relations-15111

LI, Z. (2018) The greater Eurasian partnership and the Belt and Road Initiative: Can the two be linked? Journal of Eurasian Studies, Julho de 2018, disponível em

https://journals.sagepub.com/doi/full/10.1016/i.euras.2018.07.004

LO, B. Sino-Russian Relations. Europe China Research and Advice Network, Short term policy brief 87 , Maio 2014.

LUKIN, A. China and Russia: The New Rapprochement. Polity Press, Cambridge, UK, 2018.

MACKINDER, H (1904) O pivô geográfico Da história. GEOUSP: Espaço e Tempo, 2011.

MARTINS, J. M. Q.; CEPIK, M. A. Defesa Nacional Antimíssil dos EUA: a lógica da preempção e suas implicações internacionais. In: ARTURI, Carlos S. (org.). Políticas de Defesa, Inteligência e Segurança. Porto Alegre: CEGOV, 2014.

MEARSHEIMER, J. The Tragedy of Great Powers Politics. New York: WW Norton \& Company, 2001

MELLO, L. I. A. Quem Tem Medo Da geopolítica? Editora Hucitec, 1999.

OCX, 2011. Astana Declaration on the 10th Anniversary of the SCO, disponível em disponível em http://eng.sectsco.org/documents/, acesso em 28 de novembro de 2019

PADULA, R. (2018a). "A geopolítica estadunidense e a Eurásia". Em José L. Fiori, Sobre a guerra. Petrópolis, Editora Vozes, 2018. 
PADULA, R. (2018b). O debate geoestratégico nos Estados Unidos: o lugar da Eurásia, do Hemisfério Ocidental e do México. Revista da Escola de Guerra Naval, volume 24, $\quad n^{\circ} 2, \quad$ disponível em https://revista.egn.mar.mil.br/index.php/revistadaegn/article/view/709, acesso em 4 de agosto de 2020.

PAUTASSO, D. China e Rússia no Pós-Guerra Fria. Inserção Internacional e Transição Sistêmica. Editora Juruá, Curitiba, 2013.

RIAC, 2020. Russia-China Dialogue: The 2020 Model. Russian International Affair Council, Fudan University. n`58, 2020, disponível em https://russiancouncil.ru/papers/Russia-China2020-Report58-En.pdf

SPYKMAN, N. (1942) Estados Unidos Frente al Mundo. Fondo de Cultura Economica, Panuco, Mexico, 1944.

TEIXEIRA JÚNIOR, A. W. M. A Reconfiguração do Tabuleiro Internacional e suas Implicações Geoestratégicas para o Brasil. Centro de Estudos estratégicos do Exército Vol 5 (2) Jun/ Dez 2018.

THE ECONOMIST. Russia and China: Partnership is much Better for China than it is for Russia. Edição de 27 de julho de 2019,

TREATY...2001. Tratado de Boa Vizinhança, Amizade e Cooperação (2001), disponível em https://www.voltairenet.org/article173177.html, acesso em 11 de outubro de 2019. WALTZ, Kenneth N. Theory of International Politics Long Grove, Waveland Press, 1979

WALTZ, K. Structural Realism after the Cold War. International Security, 2000, 25(1), 541. Disponível em www.jstor.org/stable/2626772, acesso em 10 de novembro de 2019.

WANG, J.: China's Search for a Grand Strategy: A Rising Great Power Finds Its Way, 2011.

YAN, X. From Keeping a Low Profile to Striving for Achievements, Chinese Journal of International Politics, Vol. 7, No. 2 (2014), pp. 153-84

\section{NOTAS DE AUTOR}

\section{CONTRIBUIÇÃO DE AUTORIA}

Ticiana de Oliveira Alvares - Concepção. Coleta de dados, Análise de dados, Elaboração do manuscrito, revisão e aprovação da versão final do trabalho

Raphael Padula - Concepção e elaboração do manuscrito. Coleta de dados Participação ativa da discussão dos resultados; Revisão e aprovação da versão final do trabalho.

\section{FINANCIAMENTO}

Não se aplica.

CONSENTIMENTO DE USO DE IMAGEM

Não se aplica.

APROVAÇÃO DE COMITÊ DE ÉTICA EM PESQUISA

Não se aplica.

CONFLITO DE INTERESSES

Não se aplica.

\section{LICENCCA DE USO}

Este artigo está licenciado sob a Licença Creative Commons CC-BY. Com essa licença você pode compartilhar, adaptar, criar para qualquer fim, desde que atribua a autoria da obra.

\section{HISTÓRICO}

